\title{
SIG Lokasi UMKM Berbasis Android
}

\author{
Moh. Rizal Pakaya \\ Prodi Sistem Informasi \\ STMIK Ichsan Gorontalo \\ Gorontalo, Indonesia \\ rizalpakayap@gmail.com
}

\author{
Olha Musa \\ Prodi Sistem Informasi \\ STMIK Ichsan Gorontalo \\ Gorontalo, Indonesia \\ 0lh4mu54@gmail.com
}

\author{
Jorry Karim \\ Prodi Sistem Informasi \\ STMIK Ichsan Gorontalo \\ Gorontalo, Indonesia \\ oyie.potlot@gmail.com
}

\author{
Syahrir Abdussamad \\ Prodi Teknik Elektro \\ Universitas Negeri Gorontalo \\ Gorontalo, Indonesia \\ syahrirabdussamad@yahoo.co.id
}

\author{
Diterima : Juni 2020 \\ Disetujui : Juli 2020 \\ Dipublikasi : Juli 2020
}

\begin{abstract}
Abstrak-Dinas Koperasi dan Usaha Mikro, Kecil dan Menengah Kabupaten Gorontalo sebagai unit pelaksana tugas daerah yang memiliki tugas untuk melakukan pembinaan dan pengembangan usaha mikro, kecil dan menengah di Kabupaten Gorontalo. Dalam melaksanakan tugas tersebut melakukan berbagai kegiatan salah satunya adalah melakukan pendataan usaha mikro, kecil dan menengah serta mensosialisasikan ke masyarakat. Dalam artikel ini, permasalahan yang timbul adalah belum tersedianya sistem informasi yang memadai kepada masyarakat tentang usaha mikro, kecil dan menengah sehingga masyarakat mengalami kesulitan mengetahui lokasi dari usaha kecil dan menengah. Tujuan dari artikel ini adalah merancang sistem informasi geografis untuk menentukan lokasi usaha mikro, kecil dan menengah berbasis android yang dapat diakses oleh masyarakat sehingga dapat memudahkan masyarakat mengetahui lokasi dari usaha mikro, kecil dan menengah yang ada di Kabupaten Gorontalo dan dapat diakses oleh masyarakat yang membutuhkan layanan informsi secara global. Artikel ini menggunakan metode Research and Development atau yang dikenal dengan metode penelitian dan pengembangan. Hasil pengujian dengan menggunakan test case membuktikan bahwa pengembangan sistem informasi geografis untuk menentukan lokasi usaha mikro, kecil dan menengah berbasis android ini lebih efektif dan efisien dengan pengujian yaitu $\mathrm{V}(\mathrm{G})=14-12+2=4 ; \mathrm{V}(\mathrm{G})=3+1=4$; dan Cyclomatic Complexity $(\mathrm{CC})=\mathrm{R1}, \mathrm{R2}, \mathrm{R3}, \mathrm{R4}=4$.
\end{abstract}

Kata Kunci: SIG, UMKM, Android

Abstract-The Office of Cooperatives and Micro, Small and Medium Enterprises in Gorontalo as a regional task implementing unit that has the task of developing and developing micro, small and medium businesses in Gorontalo Regency. In carrying out this task, a number of activities are carried out, one of which is collecting data on micro, small and medium enterprises and to socialize to the community. In this article, the challenge that arises is the unavailability of an adequate information system for the community about micro, small and medium enterprises so that people have difficulty understanding the location of small and medium businesses. The purpose of this article is to discuss geographic information systems to determine the location of android-based micro, small and medium businesses that can be accessed by the community so that it can make it easier for the public to find out the location of micro, small and medium businesses in Gorontalo District and can be accessed by people who need it global information services. This article uses the Research and Development method or what is known as the research and development method. The test results using test cases prove the development of information systems to determine the location of micro, small and medium businesses based on Android is more effective and efficient with testing namely $V(G)=14-12+2=4 ; V(G)=3+1=4$; and cyclomatic complexity $(C C)=R 1, R 2, R 3, R 4=4$.

Keywords: GIS, UMKM, Android

\section{Pendahuluan}

Sistem Informasi Geografis [1], merupakan suatu komponen yang terdiri dari perangkat keras, perangkat lunak, data geografis dan sumber daya manusia yang bekerja bersama secara efektif untuk memasukan, menyimpan, memperbaiki, memperbaharui, mengelola, memanipulasi, meng-integrasikan, menganalisa dan menampilkan data dalam suatu informasi berbasis geografis. Aplikasi sistem informasi geografis [1], saat ini tumbuh tidak hanya secara jumlah Aplikasi namun juga bertambah dari jenis keragaman Aplikasinya. Pengembangan aplikasi GIS kedepannya mengarah kepada aplikasi berbasis android. Hal ini disebabkan karena pengembangan aplikasi di lingkungan internet telah menunjukan potensi yang besar dalam kaitannya dengan geo informasi. Sebagai contoh adalah adanya peta online sebuah kota berbasis android dimana pengguna dapat dengan mudah mencari lokasi yang diinginkan secara online melalui smartphone android tanpa mengenal batas geografi penggunanya.

Dinas Koperasi dan UMKM Kabupaten Gorontalo sebagai unit pelaksana tugas daerah yang memiliki tugas untuk melakukan pembinaan dan pengembangan UMKM dalam wilayah Kabupaten Gorontalo, dalam melaksanakan tugas tersebut melakukan berbagai kegiatan salah satunya adalah melakukan pendataan usaha mikro kecil dan menengah dan mensosialisasikan ke masyarakat [2].

Dari hasil penelitian pada Dinas koperasi dan UMKM Kabupaten Gorontalo peneliti mendapatkan permasalahan yaitu belum tersedianya informasi yang memadai kepada masyarakat tentang usaha kecil dan menengah sehingga 
masyarakat mengalami kesulitan mengetahui lokasi dari usaha kecil dan menengah dan informasi lainnya yang dibutuhkan masyarakat dalam wilayah Kabupaten Gorontalo.

Berdasarkan permasalahan yang disebutkan perlu adanya solusi dalam menjawab permasalahan tersebut. Sistem informasi geografis merupakan solusi alternatif yang dapat membantu Dinas koperasi dan UMKM Kabupaten Gorontalo untuk memberikan informasi tentang lokasi usaha kecil mikro dan menengah, sehingga dapat memudahkan masyarakat mengetahui lokasi dari usaha kecil dan menengah serta informasi lainnya yang dibutuhkan masyarakat dalam wilayah Kabupaten Gorontalo.

Tujuan artikel ini adalah merancang sistem informasi geografis lokasi usaha kecil dan menengah berbasis android yang dapat diakses oleh masyarakat sehingga dapat memudahkan masyarakat mengetahui lokasi dari usaha kecil dan menengah serta informasi lainnya yang dibutuhkan masyarakat dalam wilayah Kabupaten Gorontalo.

Artikel ini dibuat tidak lepas dari hasil-hasil penelitian terlebih dahulu yang pernah dilakukan sebagai bahan kajian hasil penelitian yang dijadikan perbandingan.

Hasil penelitian dari S. N. M. Rachman [3] STMIK Amikom Yogyakarta dengan judul penelitian Sistem Informasi Geografi Pariwisata Kota Yogyakarta Berbasis Mobile Android 2.2. Arduino telah banyak dimanfaatkan diantaranya pada aplikasi sistem peringatan dini, penetas telur $[4,5]$ dan jam digital penentu waktu sholat [6]. Kesimpulan dari hasil penelitian ini adalah sistem informasi geografis pariwisata berbasis mobile android sudah berjalan baik. Sistem ini dapat memberikan informasi letak obyek wisata dan fasilitas pendukung lengkap dengan foto dan nomor telepon fasilitas pendukung dan pengguna dapat melakukan panggilan langsung dari sistem. Sistem Informasi Geografi Pariwisata Berbasis Mobile Android ini bersifat interaktif, yaitu adanya interaksi antar pengguna dengan sistem. Artinya jika pengguna memilih obyek wisata, atau fasilitas pendukung wisata lainnya maka sistem akan memberikan informasi sesuai dengan pilihan dari pengguna.

Hasil penelitian dari S. R. Nursuci [7] dalam jurnal publikasi Universitas Gunadarma dengan judul penelitian Sistem informasi geografi tempat ibadah di Kota Bogor Berbasis web dengan menggunakan Quantum Gis. Kesimpulan dari penelitian ini adalah dengan SIG tempat ibadah di Kota Bogor wisatawan sebagai user aplikasi ini dapat secara mudah memperoleh informasi mengenai letak tempat ibadah yang dimaksud. Jika wisatawan sebagai user aplikasi SIG ini mengklik salah satu simbol tempat ibadah pada peta maka dialog box hasil query pencarian akan muncul yang berisi informasi nama tempat ibadah, alamat, nomor telepon tempat ibadah tersebut. Hal ini dapat menjadi pertimbangan sehingga wisatawan dapat memutuskan apakah mereka akan mempergunakan tempat ibadah tersebut atau tidak dan memilih tempat ibadah lain yang tersedia. Selain itu, waktu pencarian user menjadi lebih singkat karena aplikasi SIG ini termasuk peta tematik dengan kemudahan yang tidak dimiliki oleh peta konvensional. Aplikasi SIG akan menampilkan hasil query tempat ibadah berdasarkan kategori yang dibutuhkan oleh user sedangkan di peta konvensional para user harus mencari dengan lebih teliti dalam mencari tempat ibadah yang diperlukan karena pada peta konvensional lokasi tempat ibadah tersebut berbaur dengan banyak fasilitas umum dan tempat lainnya di kota Bogor. Aplikasi SIG ini memiliki interface yang menarik, tools, dan simbol-simbol (legenda) untuk membantu pengguna dalam mencari letak dari tempat-tempat ibadah di kota Bogor. Tools yang dimiliki aplikasi SIG ini dapat dipergunakan untuk memperbesar dan memperjelas daerah peta yang diinginkan atau memperkecilnya. Selain memperbesar user juga dapat menggeser lokasi tempat ibadah ke arah tengah peta maupun ke arah yang diinginkan user. User dapat memperoleh semua atau sebagian lokasi tempat ibadah di kota Bogor dengan memanfaatkan tools legend yang ada.

Hasil penelitian dari H. Ravasia [8] Jurusan Sistem Informasi Universitas Gunadarma dengan judul penelitian Aplikasi Sistem Informasi Sekolah Menengah Atas Di Jakarta Utara Berbasis Android. Kesimpulan dari penelitian ini adalah Penulis melakukan pengumpulan data dengan cara pengambilan data langsung di Suku Dinas Pendidikan Menengah Jakarta Utara, analisa peta digital yaitu Google Map untuk mendapatkan data titik koordinat, kemudian melakukan perancangan sistem, pembuatan aplikasi menggunakan Eclipse dan melakukan tahap uji coba aplikasi melalui emulator Android. Aplikasi ini memberikan informasi mengenai profil Sekolah Menengah Atas dan menampilkan peta lokasi serta fasilitas pencarian SMA yang memberikan kemudahan bagi pengguna untuk mencari informasi SMA dengan memasukkan nama SMA yang dicari. Aplikasi ini dikembangankan menjadi aplikasi berbasis mobile yaitu berbasis Android, sehingga dapat digunakan dimana saja dan kapan saja, selama pengguna memiliki koneksi ke internet untuk mengakses peta yang disediakan oleh Google dan mengaktifkan fitur GPS pada perangkat yang digunakan sehingga aplikasi dapat mendapatkan lokasi dari pengguna. Aplikasi ini mempunyai tampilan yang mudah digunakan karena rancangan yang sederhana dan praktis sehingga mudah dimengerti oleh pengguna.

Perbedaan penelitian yang dilakukan oleh penulis, dengan penelitian yang dilakukan pada penelitian yang menjadi rujukan yaitu pada lokasi penelitian dan objek penelitian.

\section{METODE}

Artikel ini menggunakan metode Research and Development atau yang dikenal dengan metode penelitian dan pengembangan. Metode ini didefinisikan sebagai metode penelitian yang digunakan untuk menghasilkan produk tertentu dan menguji keefektifan produk tersebut [9].

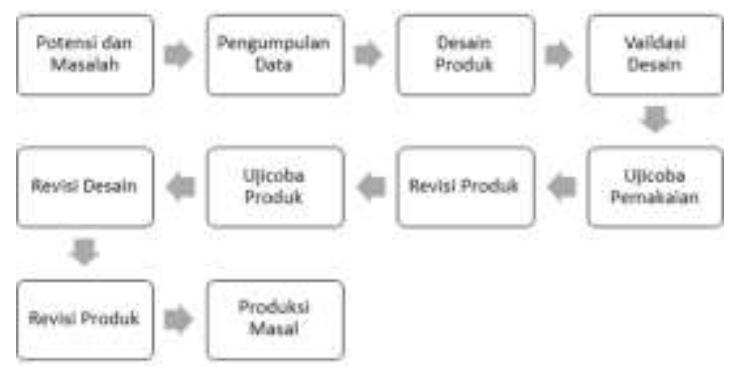

Gambar 1. Metode Research And Development 
Research and Development membagi metode menjadi 3 bagian dalam penelitian [9] yaitu: Deskriptif; Evaluatif dan Eksperimen.

\section{A. Tahap Analisis}

Sulitnya mengetahui lokasi dan informasi yang berhubungan dengan usaha mikro, kecil dan menengah yang ada di Kabupaten Gorontalo yang menjadi masalah dalam artikel ini.

\section{Jenis dan Sumber Data}

Data primer merupakan data mentah yang diperoleh secara langsung melalui survey dengan pihak Dinas Koperasi dan UMKM Kabupaten Gorontalo yang berhubungan dengan penelitian yang sedang dilakukan, kemudian akan diolah untuk pembuatan perancang sistem informasi yang dibutuhkan; Data sekunder yaitu data yang diperoleh dari sumber sekunder, penulis mengumpulkan data-data yang ada berupa pengambilan contoh ataupun dokumendokumen, jurnal ataupun buku-buku referensi yang ada kaitannya dengan penulisan ini.

\section{B. Metode Pengumpulan Data}

Teknik pengumpulan data dilakukan dengan cara: Survei, Pengumpulan data dengan melakukan survei ke Dinas Koperasi dan UMKM Kabupaten Gorontalo dan memperoleh data-data berupa data usaha kecil dan menengah dalam wilayah Kabupaten Gorontalo; Studi Pustaka, Pengumpulan data dengan cara membaca serta mempelajari dokumen, literatur, buku, jurnal yang berhubungan dengan obyek penelitian guna mendapatkan teori ataupun konsep yang dapat digunakan.

\section{Analisa Sistem yang Berjalan}

Dalam sistem berjalan terdiri dari 3 aktor, yaitu: staf, seksi bimbingan usaha perdagangan, dan kepala dinas. Analisa sistem yang berjalan dibuat untuk menggambarkan alur atau proses model pada sistem yang lama pada bagian yang di teliti permasalahannya, sehingga kita dapat mengetahui letak masalah dan membuatkan solusinya.

\section{Analisa Sistem yang Diusulkan}

Aktor pada sistem yang diusulkan ada 3 yaitu admin adalah pegawai di Dinas Koperasi dan UMKM Kabupaten Gorontalo. Pengguna adalah masyarakat umum dan pengelola usaha yang merupakan pelaku usaha di bidang usaha kecil dan menengah. Sistem yang diusulkan berusaha untuk mengatasi permasalahan yang ditemui pada sistem yang sedang berjalan khususnya untuk memudahkan mengetahui lokasi dan informasi lainnya yang berhubungan dengan usaha kecil dan menengah.

\section{Tahap Rancangan}

Adapun tahap pertama dari rancangan sistem yaitu arsitektur dan pemodelan aplikasi, dimana pada tahap ini kita melakukan pertimbangan-pertimbangan mengenai bagaimana suatu sistem akan diterapkan, baik dalam teknologi dan lingkungan implementasi. Pada tahap ini digunakan Unified Modelling Language (UML), dimana kita memodelkan persyaratan bisnis logis dari suatu sistem informasi.
Selanjutnya dilakukan tahap rancangan basis data, dimana semua proses membuat, membaca, memperbaharui, dan menghapus (create, read, update, delete) data. Data disimpan dalam file dan basis data. Termasuk dalam tahap ini adalah pemodelan field kunci, record table, relasi basis data, entitas data. Kemudian masuk pada tahap rancangan dan prototyping input dan output serta antar muka sistem, menggambarkan masukan dan keluaran bagi pengguna sistem, baik dalam bentuk formulir masukan, sistem organisasi menu, bentuk cetakan kertas ataupun tampilan ke layar monitor. Implementasi masukan merupakan masukan masukan dari keyboard dan mouse, penyesuaian tipe pengguna sistem, penggunaan gambar dan simbol (icon).

\section{Tahap Pengujian}

Melakukan pengetesan terhadap sistem yang telah selesai dibuat sebelum diimplementasikan dengan menggunakan teknik pengujian perangkat lunak yang telah ada yakni menggunakan pengujian White Box dan Black Box Testing.

\section{E. Tahap Implementasi}

Tahap implementasi sistem yaitu tahap meletakkan sistem agar siap untuk dioperasikan. Penerapan sistem ini yaitu pada Dinas Koperasi dan UMKM Kabupaten Gorontalo dan admin adalah staf bimbingan usaha perdagangan pada Dinas Koperasi dan UMKM Kabupaten Gorontalo.

\section{HaSil dan PeMbahasan}

\section{A. Hasil}

Setelah perancangan sistem informasi lokasi jasa pemesanan percetakan di buat, maka yang dilakukan selanjutnya adalah:

\section{Analisis Sistem}

Usecase diagram digunakan untuk menggambarkan peran setiap aktor terhadap sistem berjalan dan sistem yang direncanakan.

\section{Sistem yang Sedang Berjalan}

Sulitnya untuk mengetahui lokasi dan informasi lainnya yang berhubungan dengan usaha kecil dan menengah merupakan penyebab dari sistem yang sedang berjalan.

Use-case sistem yang sedang berjalan, diketahui bahwa user yang terlibat dalam sistem ada 3, yaitu staf seksi bimbingan usaha perdagangan, seksi bimbingan usaha perdagangan, dan kepala dinas. Pada sistem yang berjalan, seksi bimbingan usaha perdagangan dapat melakukan pendataan UMKM, mengelompokkan UMKM per bidang usaha. Sedangkan seksi bimbingan usaha perdagangan membuat laporan data UMKM dan diserahkan ke kepala dinas. Sedangkan kepala dinas menerima laporan data UMKM.

\section{Sistem yang Direncanakan}

Hasil analisis sistem yang sedang berjalan, ditemukan faktor yang menyebabkan permasalahan tersebut terjadi. Oleh karena itu dengan menggunakan metode yang dipilih peneliti, maka mengusulkan rancangan sistem untuk mengatasi permasalahan yang terjadi. 
Narasi dari sistem yang diusulkan adalah sebagai berikut: ada tiga aktor dalam proses yaitu Administrator, pengusaha UMKM dan pengguna. Proses dimulai dari aktor Administrator melakukan login dengan user pengguna administrator, selanjutnya melakukan pengisian data kecamatan berisi data kecamatan yang ada dalam wilayah Kabupaten Gorontalo, selanjutnya pendataan bidang usaha berisi data bidang-bidang usaha kecil dan menengah, dilanjutkan dengan pendataan lokasi usaha UMKM berisi data usaha-usaha UMKM dalam wilayah Kabupaten Gorontalo, selanjutnya mendata koordinat lokasi UMKM berisi data geografis lokasi UMKM yang telah di input pada pendataan lokasi UMKM sebelumnya, selanjutnya aktor pengusaha UMKM melakukan login pengusaha dengan user pengguna pengusaha yang akan didapatkan dari pengisian data lokasi usaha UMKM pada Administrator, dilanjutkan dengan pengisian data kelengkapan profil apabila data profil usaha belum lengkap, selanjutnya dilakukan pengisian data produksi berisi data produksi usaha apa sajayang dimiliki oleh UMKM tersebut sebagai informasi ke masyarakat. Selanjutnya aktor pengguna diawali dengan melihat list/daftar lokasi usaha UMKM, selanjutnya menampilkan data, dari pilihan usaha, aktor pengguna juga bisa melihat daftar usaha UMKM dalam bentuk peta melalui peta lokasi UMKM, selanjutnya ditampilkan rute berdasarkan lokasi usaha yang dipilih.

\section{Rancangan Input Secara Umum}

Rancangan input merupakan tahapan perancangan suatu tampilan yang dijadikan sebagai dasar dokumen yang akan digunakan untuk mengarsipkan data yang akan diproses untuk mendapatkan keluaran (output) untuk input data dilakukan melalui websited dan Android Aplikasi.

\section{Form Login Web}

Tampilan form Gambar 2 digunakan oleh user untuk masuk ke dalam sistem. Untuk masuk ke dalam sistem user harus menginputkan username dan password. Jika password yang diinputkan benar maka secara otomatis halaman akan berpindah ke beranda, jika salah maka halaman akan menampilkan pesan salah.

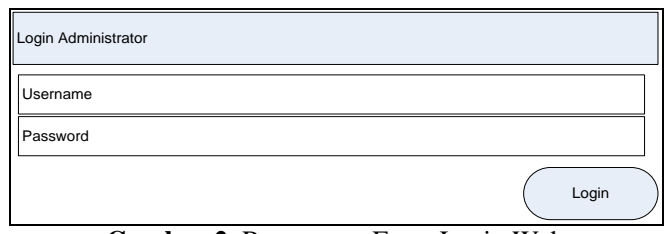

Gambar 2. Rancangan Form Login Web

\section{Form Input Data Kecamatan}

Tampilan form Gambar 3 digunakan oleh admin untuk input data kecamatan, berupa pengisian data kode kecamatan dan nama kecamatan. Simpan digunakan untuk memproses data dan batal untuk kembali ke halaman utama.

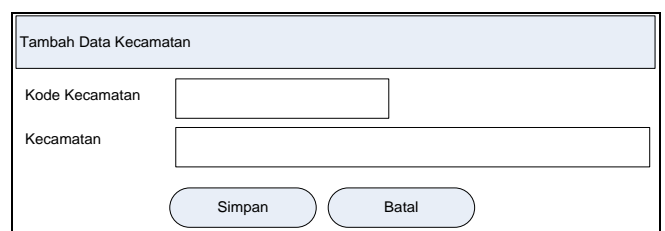

Gambar 3. Rancangan Form Input Data Kecamatan

\section{Form Input Data Bidang Usaha}

Tampilan form Gambar 4, digunakan oleh admin untuk input data bidang usaha, berupa pengisian data kode bidang dan nama bidang. Simpan digunakan untuk memproses data dan batal untuk kembali ke halaman utama.

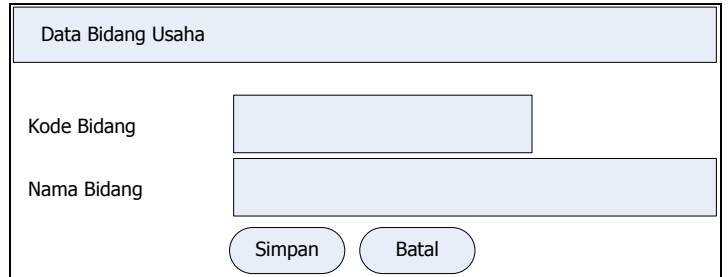

Gambar 4. Rancangan Form Input Data Bidang Usaha

\section{Form Input Data Lokasi Usaha}

Tampilan form Gambar 5 digunakan oleh admin untuk input data lokasi usaha UMKM, berupa pengisian data usaha. Simpan digunakan untuk memproses data dan batal untuk kembali ke halaman utama.

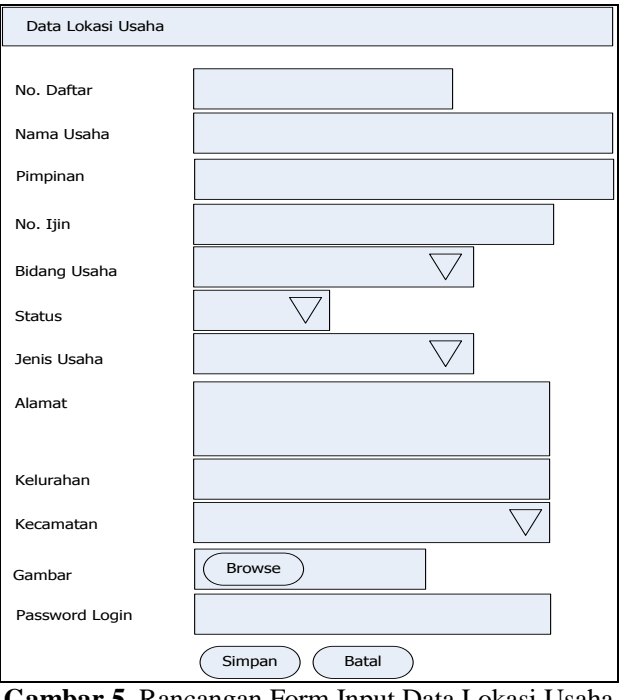

\section{Form Input Data Koordinat Lokasi Usaha}

Tampilan form Gambar 6 digunakan oleh admin untuk input data koordinat lokasi usaha UMKM, berupa pengisian data latitude dan longitude lokasi yang di sesuaikan dengan koordinat google maps. Simpan digunakan untuk memproses data dan batal untuk kembali ke halaman utama.

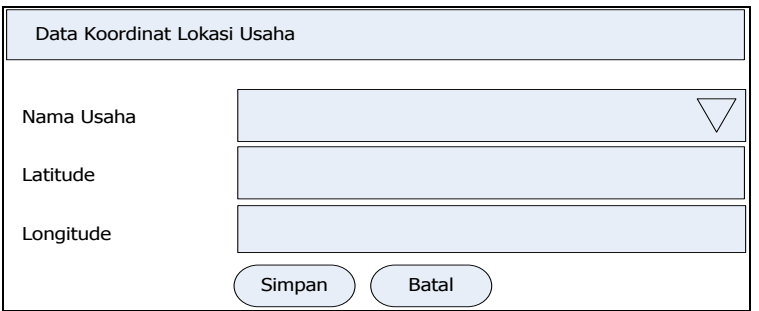

Gambar 6. Rancangan Form Input Data Koordinat Lokasi Usaha 


\section{Rancangan Sistem Secara Terinci}

\section{a) Rancangan Web.}

\section{Rancangan Tampilan Login User}

Tampilan halaman login user web seperti Gambar 7 . Halaman ini akan digunakan user admin untuk login ke sistem informasi geografis lokasi UMKM di Kabupaten Gorontalo

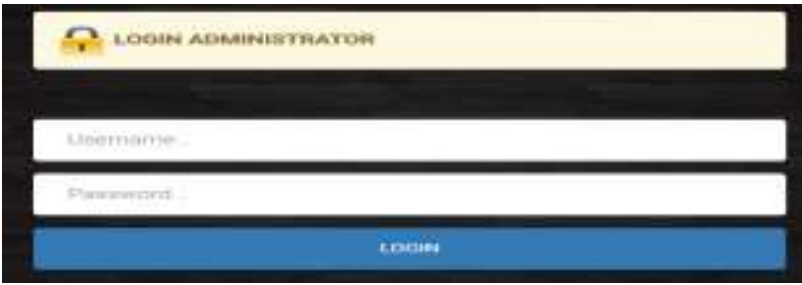

Gambar 7. Rancangan Tampilan Login User

\section{Rancangan Tampilan Utama}

Rancangan tampilan utama halaman administrator akan dirancang seperti Gambar 8. Halaman ini adalah halaman utama yang akan tampil ketika pengguna/administrator mengakses web ini.

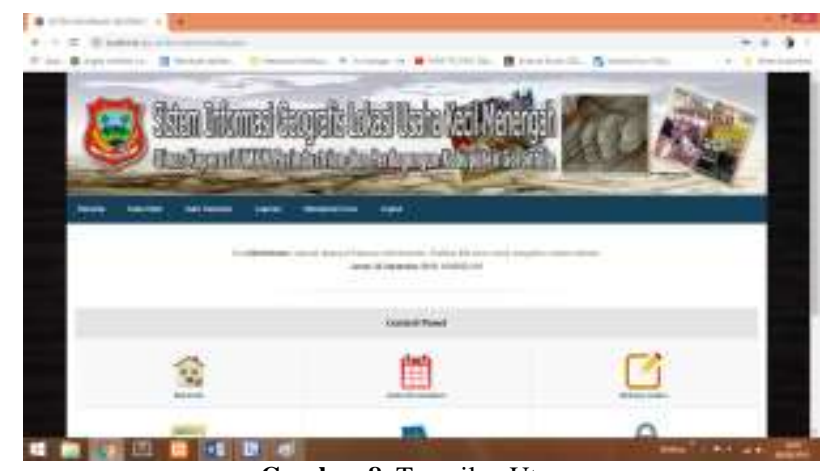

Gambar 8. Tampilan Utama

\section{Rancangan Tampilan Data Kecamatan}

Data Kecamatanakan yang akan di pakai untuk menentukan lokasi UMKM dirancang yang sebelumnya harus dimasukkan dalam basis data seperti terlihat Gambar 9 .

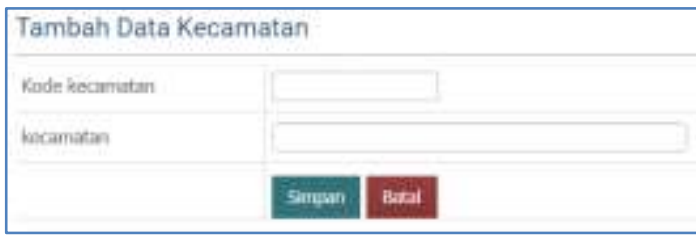

Gambar 9. Tampilan Data Kecamatan

\section{Rancangan Tampilan Data Bidang Usaha}

Data jenis usaha akan dirancang seperti pada Gambar 10. Tampilan ini untuk memasukkan data usaha UMKM dengan kode dan nama bidang usaha

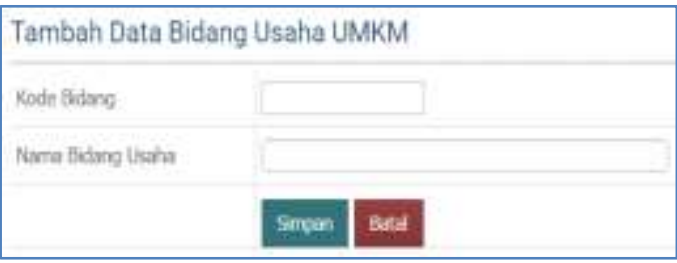

Gambar 10. Tampilan Data Bidang Usaha

\section{Rancangan Tampilan Data Lokasi Usaha Umkm}

Seperti Gambar 11, data usaha dirancang dengan memasukan data seperti nama usaha, bidang usaha, kelurahan, kecamatan dan lainnya.

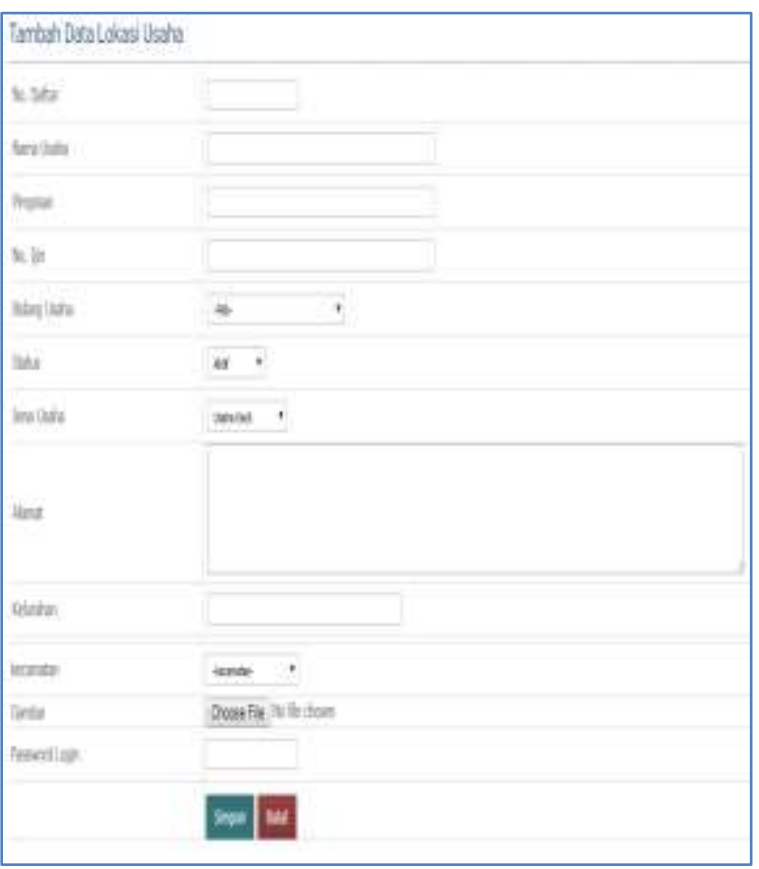

Gambar 11. Tampilan Data Lokasi Usaha UMKM

\section{Rancangan Tampilan Data Koordinat Lokasi Usaha}

Data koordinat lokasi usaha akan dirancang seperti Gambar 12 dengan menetukan nama usaha, latitude dan longitude.

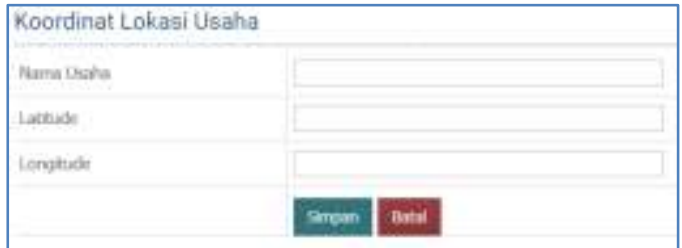

Gambar 12. Tampilan Data Koordinat Lokasi Usaha

\section{Rancangan Android.}

\section{Rancangan Tampilan Halaman Awal}

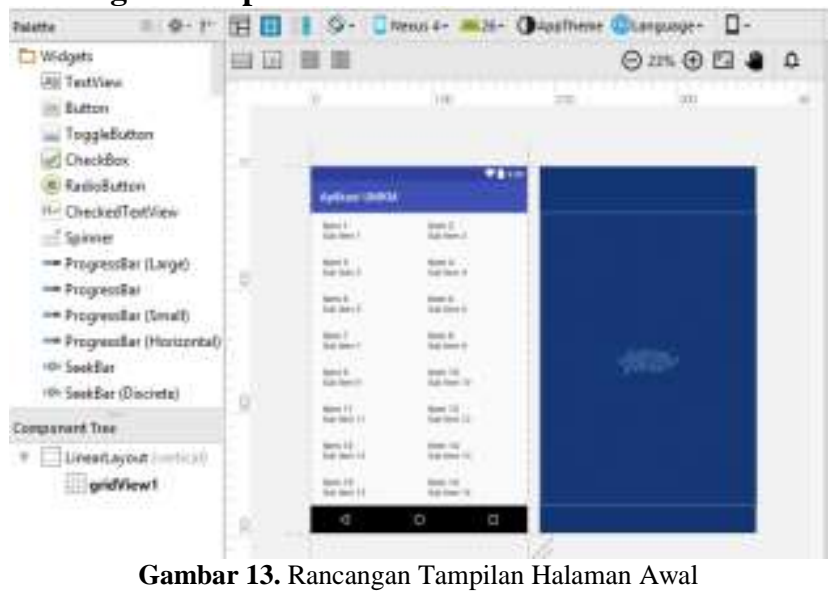

Tampilan halaman awal menggunakan android dirancang seperti Gambar 13. 


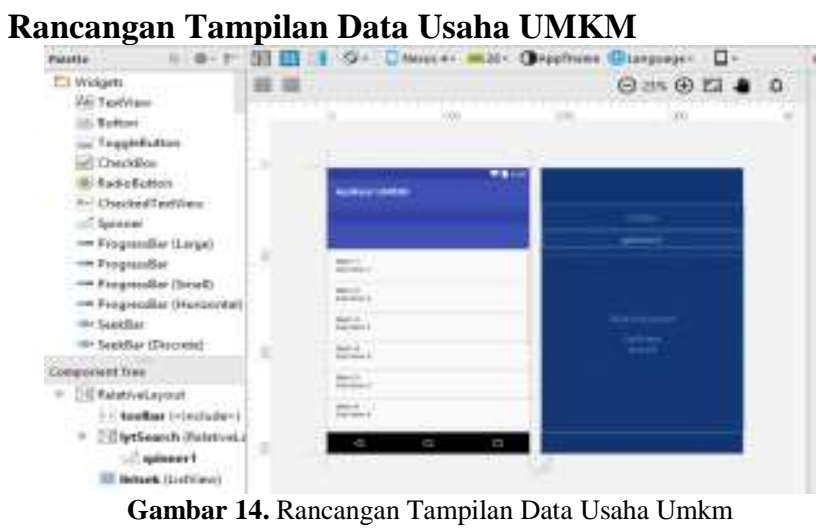

Halaman data usaha UMKM menggunakan android di rancang seperti pada Gambar 14.

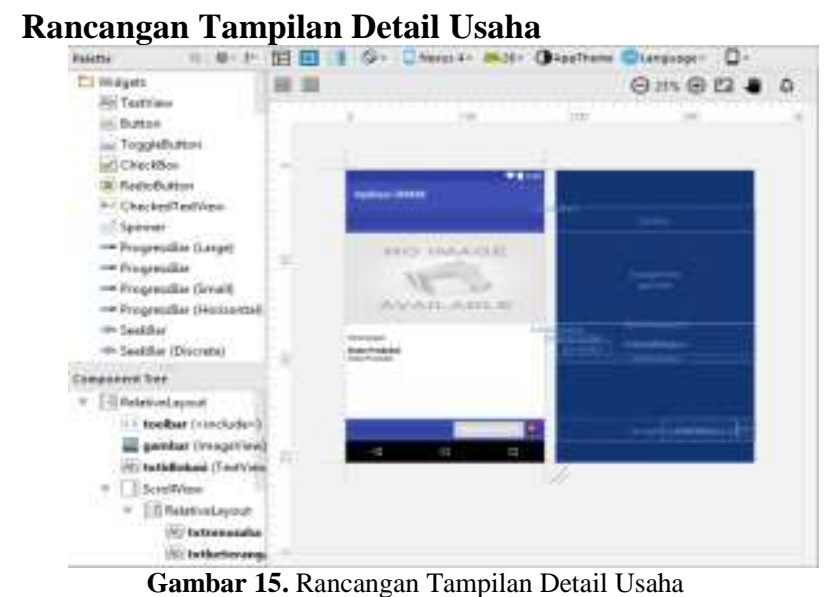

Tampilan halaman detail usaha menggunakan android di rancangan seperti tampilan pada Gambar 15.

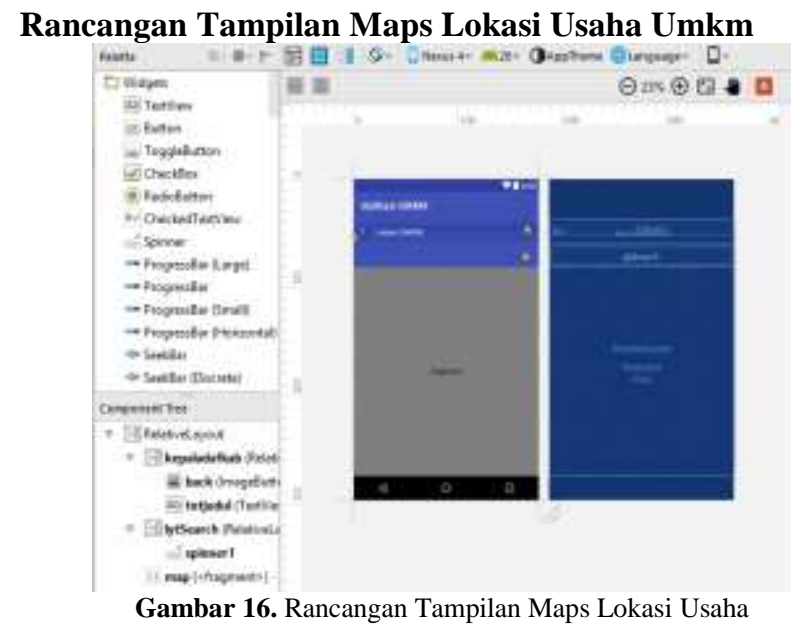

Tampilan halaman Maps Lokasi usaha menggunakan android diperlihatkan pada Gambar 16.

\section{Rancangan Output Secara Terinci}

Rancangan untuk tampilan untuk laporan data usaha UMKM diperlihatkan pada Gambar 17. Laporan data ini, akan menampilkan diantaranya nama usaha, pimpinan usaha, bidang usaha, koordinat dan alamat.

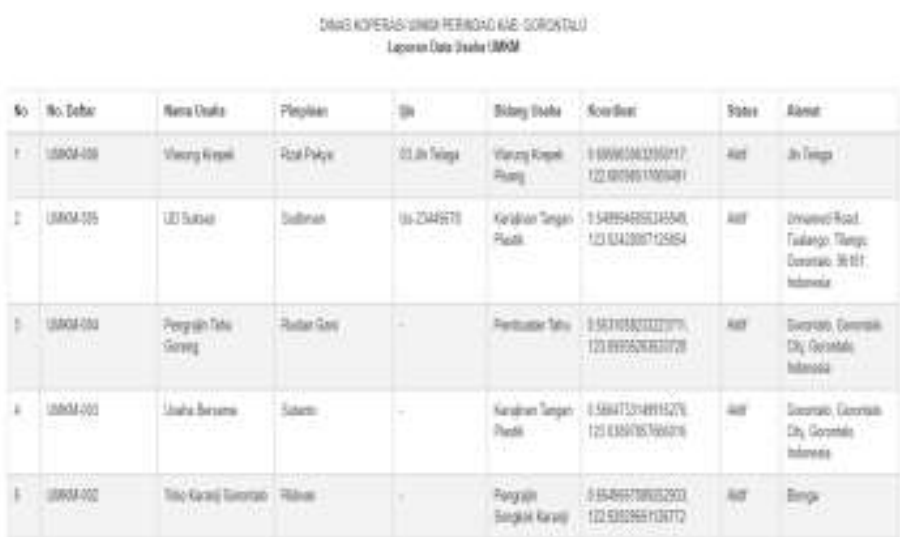

Gambar 17. Laporan Data Usaha UMKM

\section{Rancangan Graphic User Interface Client}

Tampilan Splash Screen dan menu utam awal aplikasi diperlihatkan pada Gambar 18.

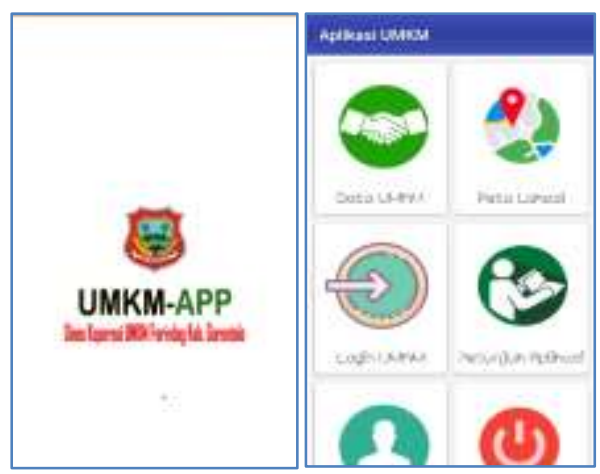

Gambar 18. Halaman Splash Screendan Halaman

Pada saat pengguna menjalankan program, maka halaman akan diarahkan ke halaman splash screen. Pada halaman ini terdapat beberapa fungsi di antaranya adalah melakukan pengecekan koneksi yang dipakai dan membuat hubungan ke server.

Setelah tampilan splash screen selanjutnya user akan diarahkan ke halaman menu utama awal aplikasi.

\section{Halaman Login dan Menu Utama Pemilik Usaha}

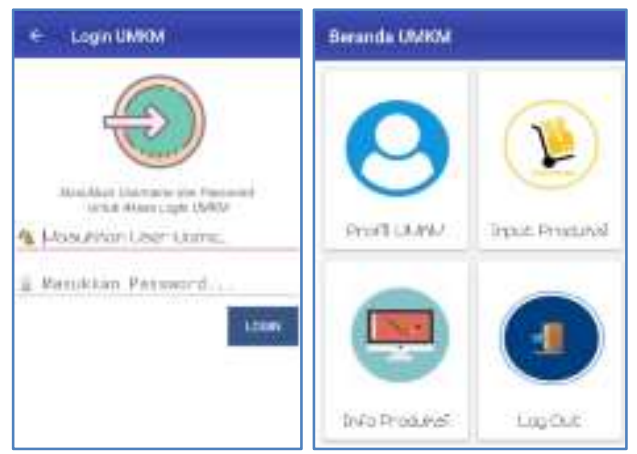

Gambar 19. Halaman Login User dan Menu Utama Pemilik UMKM

Gambar 19 adalah tampilan halaman menu utama aplikasi. Pengguna harus melakukan memilih tap menu untuk mendapatkan fungsionalitas dari tiap menu aplikasi yang ada. 


\section{Halaman Data Usaha dan Detail Usaha}

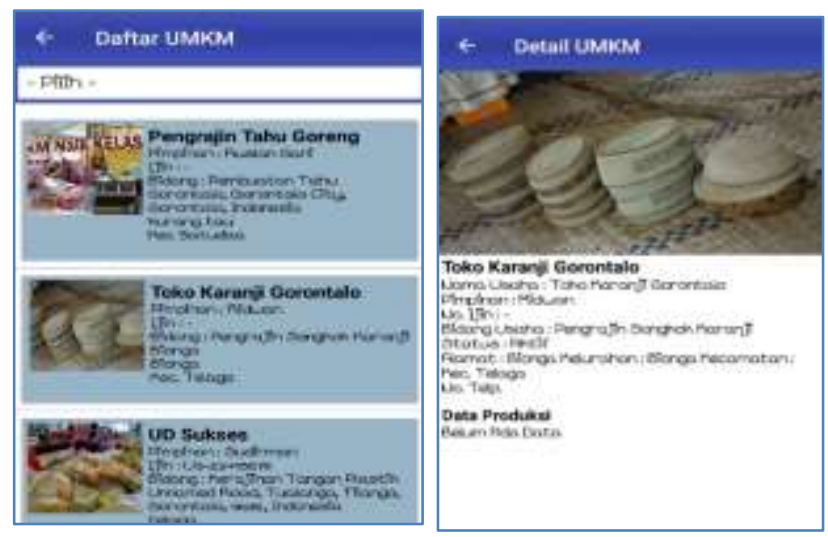

Gambar 20. Halaman Usaha dan Detail Usaha

Seperti terlihat pada Gambar 20, merupakan tampilan halaman usaha dan detail usaha. Detail usaha tampil setelah pengguna memilih salah satu usaha daftar UMKM.

\section{Halaman Data Map Lokasi Usaha dan Rute ke Lokasi}

Data map lokasi usaha dan rut eke lokasi usaha diperlihatkan pada Gambar 21. Dengan memilih lokasi UMKM dengan cara meng-klik pada titik lokasi usaha. Lokasi usaha dalam bentuk peta serta rute menuju ke lokasi sesuai koordinat akan diperlihatkan berapa lama waktu tempuh dan berapa jarak untuk sampai ke tujuan.
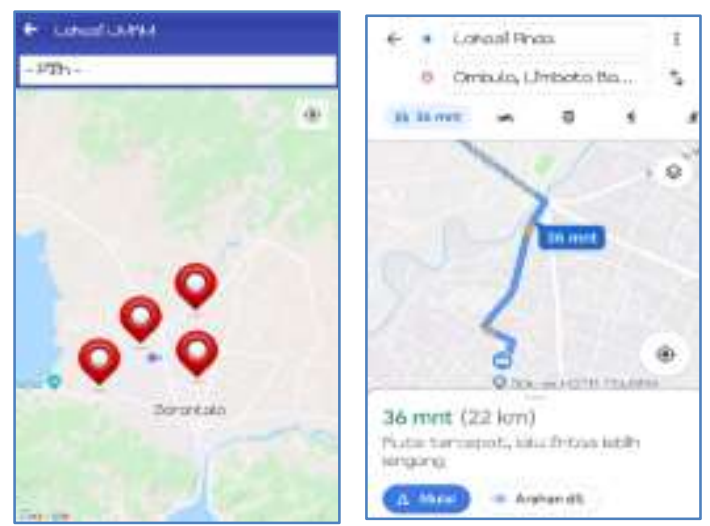

Gambar 21. Halaman Data map Lokasi dan Rute Ke Lokas

\section{B. Pengujian Perangkat Lunak}

Pengujian sistem dilakukan untuk mengukur apakah sistem yang dikembangkan telah sesuai dan dapat berjalan dengan alur yang telah direncanakan sebelumnya.

Pengujian menggunakan teknik uji coba whitebox pada alur program struktur logika program dan prosedur program dengan cara pemetaan flowchart, kemudian menghitung besarnya jumlah edge dan node, dimana jumlah edge ini akan menentukan besarnya cyclomatic complexcity. Pada perhitungan cyclomatic complexcity jika:

1. $V(G)=E-N+2$ hasilnya sama dengan $V(G)=P+1$

2. Jika flowgraph mempunyai region sama dengan jumlah $V(G)$ maka sistem sudah terbukti efektif dan efisien.

Untuk pengujian white box, artikel ini menggunakan pendataan UMKM yang dilakukan dari sisi website.

\section{a. Flowgraph}

Flowgraph seperti yang diperlihatkan pada Gambar 22 adalah modul pengisian data usaha mikro, kecil dan menengah.

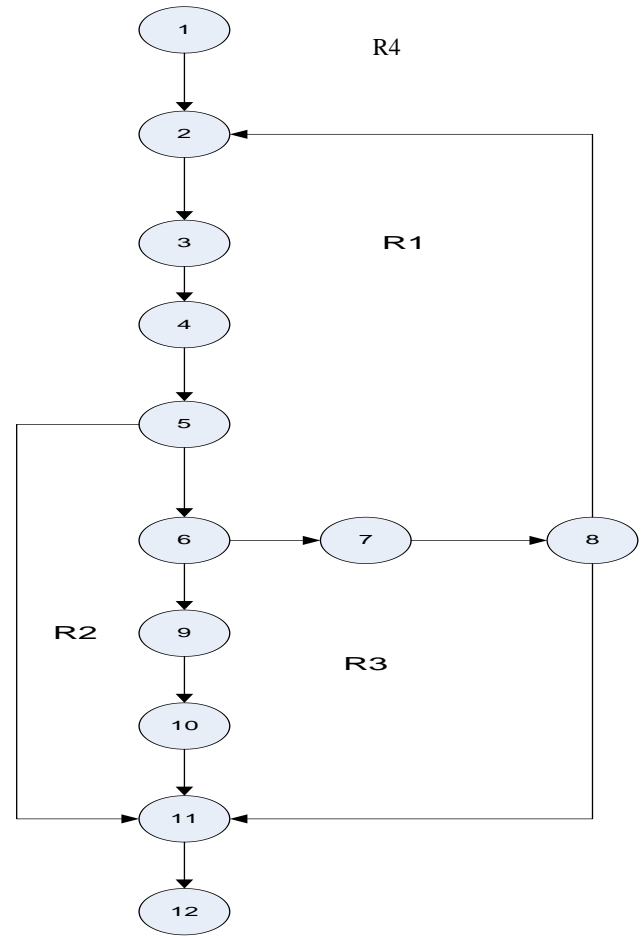

Gambar 22. Flowgraph Modul Pengisian Data UMKM

\section{b. Pseudocode}

Node 1 : Start / mulai

Node 2 : Aktifkan file bidang_usaha, kecamatan, lokasi

Node 3 : Input data usaha

Node 4 : upload gambar usaha

Node 5 : Simpan ?jika ya lanjut ke node 6, jika tidak ke node 11

Node 6 : Validasi ? jika gagal lanjut ke 7, jika sukses lanjut ke node 9

Node 7 : tampil pesan gagal

Node 8 : coba lagi ? jika ya ke node 2 jika tidak ke node 11

Node 9 : simpan data

Node 10: tampil pesan simpan data

Node 11 : tutup file

Node 12 : Finish/ selesai

\section{Perhitungan Cyclomatic Complexcity $(C C)$}

Dari flowgraph untuk modul data usaha di atas di ketahui bahwa nilai :

$$
\begin{array}{ll}
\text { - } & \text { Region }(\mathrm{R})=4 \rightarrow \mathrm{R} 1, \mathrm{R} 2, \mathrm{R} 3, \mathrm{R} 4 \\
\text { - } & \text { Predicate Node }(\mathrm{P})=3 \\
\text { - } & \text { Node }=12 \\
\text { - } & \text { Edge }=14
\end{array}
$$

1. $\mathrm{V}(\mathrm{G})=\mathrm{E}-\mathrm{N}+2$

$$
=(14-12)+2=4
$$

2. $\mathrm{V}(\mathrm{G})=($ Predicate Node $(\mathrm{P})+1)=3+1=4$

3. Ciclometic Complexity $(\mathrm{CC})=\mathrm{R} 1, \mathrm{R} 2, \mathrm{R} 3, \mathrm{R} 4=\mathbf{4}$ 


\section{c. Perhitungan Independent Path}

\section{Independent Path untuk modul pengisian data}

kelompokyaitu:

$$
\begin{aligned}
& \mathrm{R} 1=1,2,3,4,5,6,7,8,2 \ldots \\
& \mathrm{R} 2=1,2,3,4,5,11 \ldots \\
& \mathrm{R} 3=1,2,3,4,5,6,7,8,11 \ldots \\
& \mathrm{R} 4=1,2,3,4,5,6,9,10,11,12
\end{aligned}
$$

Berdasarkan hasil pengujian diperoleh :

- $\mathrm{V}(\mathrm{G})=4$

- $\quad$ Cyclometic Complexity $(\mathrm{CC})=\mathbf{4}$

Maka dapat disimpulkan bahwa alur logika untuk modul pendataan UMKM adalah efektif dan efisien.

\section{Pembahasan}

Sistem yang dirancang selanjutnya akan diimplementasikan pada Dinas Koperasi dan UMKM Kabupaten Gorontalo. Untuk aplikasi sisi server akan langsung di pasang pada Dinas Koperasi dan UMKM Kabupaten Gorontalo yang akan dioperasikan oleh staf yang ada, selanjutnya untuk aplikasi mobile akan di upload ke playstore untuk dapat di download oleh masyarakat secara gratis.

Untuk menjalankan aplikasi ini dibutuhkan smartphone dengan sistem operasi android minimum adalah Kitkat. Aplikasi ini juga membutuhkan internet untuk berkomunikasi dengan web service yang ada di sisi server.

\section{KESIMPULAN}

Simpulan dari artikel ini adalah: Sistem ini dapat memudahkan masyarakat umum untuk dapat mencari lokasi usaha-usaha UMKM yang ada di Kabupaten Gorontalo dan bisa diakses dari mana saja; Hasil perhitungan Cyclomatic Complexity (CC) dari flowgraph untuk modul order percetakan di ketahui bahwa nilai: Region $(\mathrm{R})=4 \rightarrow \mathrm{R} 1, \mathrm{R} 2$, $\mathrm{R} 3, \mathrm{R} 4 ;$ Predicate Node $(\mathrm{P})=3 ;$ Node $=12 ;$ Edge $=14$. Dengan perhitungan V $(\mathrm{G})=\mathrm{E}-\mathrm{N}+2 ;=(14-12)+2=4 ; \mathrm{V}$ $(\mathrm{G})=($ Predicate Node $(\mathrm{P})+1)=3+1=4 ; \quad$ Cyclomatic Complexity $(\mathrm{CC})=\mathrm{R} 1, \mathrm{R} 2, \mathrm{R} 3, \mathrm{R} 4=4$; dengan perhitungan Independent Path $\mathrm{V}(\mathrm{G})=4$; Cyclomatic Complexity $(\mathrm{CC})=$ 4. Pengujian sistem yang dihasilkan dalam rancangan ini lebih efektif dan efisien.

\section{REFFERENSI}

[1] C. Denny, Desain dan Aplikasi GIS, Geographic Information System, Jakarta: PT. Gramedia, 2012.

[2] "Profil Dinas Koperasi dan UMKM Kab. Gorontalo, Dinas Koperasi dan UMKM Kabupaten Gorontalo, Kabupaten Gorontalo, 2014.

[3] S. N. M. Rahman, "Sistem Informasi Geografis Pariwisata Kota Yogyakarta Berbasis Mobile Android," STMIK Amikom, Yogyakarta, 2012.

[4] F.R. Usman, W. Ridwan, I.Z. Nasibu, Sistem Peringatan Dini Bencana Banjir Berbasis Mikrokontroler Arduino, Jambura Journal of Electrical and Electronics Engineering, Vol. 1 No. 1 Januari 2019.

[5] M. R. Wirajaya, S. Abdussamad, I.Z. Nasibu, Rancang Bangun Mesin Penetas Telur Otomatis Menggunakan Mikrokontroler Arduino Uno, Jambura Journal of Electrical and Electronics Engineering, Vol. 2 No. 1 Januari 2020.

[6] Y.H. Kanoi, S. Abdussamad, S.W. Dali, Perancangan Jam Digital Waktu Sholat Menggunakan Arduino Uno, Jambura Journal of Electrical and Electronics Engineering, Vol. 1 No. 2 Juli 2019.

[7] S. R. Nursuci, Sistem informasi geografi tempat ibadah di Kotc Bogor Berbasis web dengan menggunakan Quantum Gis, jurnal publikasi Universitas Gunadarma, 2010.
[8] H. Ravasia, Aplikasi Sistem Informasi Sekolah Menengah Atas Di Jakarta Utara Berbasis Android. Sistem Informasi Universitas Guna Dharma, Depok, Jawa Barat, 2013.

[9] Sudaryono, S. Guritno and U. Rahardja, Theory and Application of IT Research, Yogyakarta: Andi Offset, 2011. 